\title{
Assessing Value-Based Plans in Public R\&D Using the Analytic Hierarchy Process
}

\author{
Pawadee Meesapawong, Yacine Rezgui, and Haijiang Li \\ School of Engineering, Cardiff University, Queen's Buildings, The Parade, Cardiff, CF243AA, \\ Wales, United Kingdom \\ \{MeesapawongP, RezguiY, LiH\}@cardiff.ac.uk
}

\begin{abstract}
There is a need for research regarding how to manage public research and development (R\&D) to create societal values. The paper focuses on the Analytic Hierarchy Process (AHP) in a case study, the microelectronics research center. Twenty-four factors (e.g. mission, internal R\&D, collaboration and management-related factors) were constructed in a hierarchy model for assessing three innovation plans: knowledge, societal and commercial orientation. The AHP analysis reveals that commercial orientation has the highest impact score on innovation factors. However, given that the selected case study is a taxpayer-funded public R\&D organisation, societal expectations have to be factored into their innovation plans. Hence, the paper provides a sensitivity analysis as a result of which a suggestion is made to increase the priority of collaboration-related factors to improve the impact of societal orientation.
\end{abstract}

Keywords: AHP, collaboration, innovation, public R\&D, societal value.

\section{Introduction}

Managing research and development (R\&D) needs more efforts to develop innovation models which span multiple dimensions such as individual, organisational, and environmental [1]. Environmental factors influencing corporate innovations involve the customer dimension, i.e. how to carry out customer-oriented innovations [1], [2]. In contrast, taxpayer-funded organisations should not only serve specific customers but also serve general citizens, thus focusing on societal-oriented innovations [3], [4]. However, many taxpayer-funded R\&D organisations have failed to create values to theirs nations [1], [5].

Additionally, values can be created at different levels: individual, organisational, and societal level [6]. The individual values that employees perceive in a given situation influence the overall values of an organisation [7]. The important issue for employees is what the organisations values are. Societal values can guide expressions of individuals and organisations, however, individual perceptions to societal values are non-systematic approaches. Employees tend to respond to performance evaluations whether or not they meet such values. Organisations have to realise which functional areas are relevant to societal values and shape perception of those areas 
into systematic approaches [8]. However, value orientations within societies change over time, thus proactive organisations learn to respond to societal influences [8].

The authors identify a research gap in that there have been very few studies on how to manage innovations in public R\&D [9]. Organisations may build collaborative networks in order to perform meaningful contribution [3], [4]. Hence, this paper first reviews existing collaborative networks in R\&D. Next, the consolidation of the Analytic Hierarchy Process (AHP) to achieve a hierarchy model for corporate innovations in public R\&D is described. The AHP findings in the selected case study, namely 'MEC', are then further discussed. The final section draws out the contribution of the paper and provides the directions for further research.

\section{Collaboration Dimension in R\&D}

Innovation has become an important aspect of organisational management. It has been defined broadly in different contexts and usually the word 'new' is emphasised. Managing innovation is a process to find the proper ways involving all the activities in turning new ideas into widely used practice such as commercialisation [10]. There has been a growing awareness in a crucial role of collaborative networks in innovation performance [1], [11], [12]. Private R\&D organisations collaborate with others for several economic reasons, such as reducing cost, reducing time, reducing risk and achieving high novelty degrees of innovations [10], [11]. For public R\&D organisations, however, the reasons to initiating collaboration may be slightly different. Some public R\&D organisations have been spurred to collaborate with universities and firms because of the growth of societal expectations and factors related to national policies [13].

To achieve successful collaboration, public R\&D has to communicate with internal and external players. For internal players, public R\&D needs to motivate employees with clear understanding of responsibilities and clear policies for commitments such as time-limited policies [1]. For external players, budget constraints force public R\&D to select potential projects and make the decision whether funding is on the basis of repayment, non-repayment or repayable if successful [5], [13]. Performance of collaboration can be assessed both in terms of tangible and intangible values. The tangible values are new products which meet societal expectations and intellectual properties for innovation competitiveness. The intangible values include, for example, that professional researchers in public R\&D help industries which lack human capital [1]. An important role of collaborative $R \& D$ leads to a growing need for new perspectives on innovation management in $R \& D$ [14]. R\&D should emphasis strong and strategic linkages amongst collaborating stakeholders. The model of innovation management should increase importance of societal ingredients such as having the potential to capture knowledge originating from social interactions [15]. However, a business model of an organisation should represent of what value is provided to customers [16]. In addition, innovation management encompasses all the key activities needed to develop successful products and services [10], thus the authors argue that the innovation model should not only focus on the performance of collaboration, but also the other organisational dimensions. 
Meesapawong et al. [9] proposed an innovation model involving four dimensions of public $R \& D$ : the mission of public $R \& D$, internal $R \& D$, collaborative projects, and management. They advocated that public R\&D organisations should focus on nurturing values from these four dimensions. Furthermore, Meesapawong et al. [17] employed the Delphi method, an expert-based judgment, to provide the factors associated to each dimension which are essential for applying the proposed framework in public R\&D. However, the Delphi findings could not provide a clearcut rank of the factors. Moreover, the level of importance of the collaboration-related factors is what constitutes the focus of the research?

\section{$3 \quad$ Methodology}

To address research gap of practicing collaborative projects to stimulate innovations in public $\mathrm{R} \& \mathrm{D}$, the authors employ the AHP to provide a clear-cut rank of collaboration-related factors including an authoritative model to manage innovations in practice.

The AHP is a widely used tool in solving a complex problem involving tangible and intangible factors. Breaking down a decision problem into a hierarchical structure makes decisions more comfortably than rating the large number of items [18], [19], [20]. The unequal priorities by which alternatives are evaluated could be used as supporting information to describe how changes of the factors affect scores of alternatives [18], [21]. Although many studies propose that the combination of the AHP and Fuzzy theory can handle uncertainty of decision making, Saaty [22], who first introduced the AHP, states that the way in which the Fuzzy approach reduces inconsistency judgments distort the original priorities and makes the validity of the outcome worse.

The research focuses on a case study drawn from Thailand, the same country as selected in the Delphi study of Meesapawong et al. [17] because conducting research across countries may face results diversity stemmed from socio-cultural differences [23]. The AHP case study is the first integrated circuits fabrication research center in Thailand, namely MEC (the name has been disguised for confidentiality issues). MEC is fully funded by Thai government to develop commercialised products and to collaborate with local industries. The current shrinking of governmental budget forces MEC to plan a management model to deal with its complex missions. Thus, the AHP is employed to select a proper plan of managing future innovations in MEC.

The first step of adapting AHP for innovation planning in MEC is to construct a pre-determined hierarchy and then discuss it with MEC's managers. The top level of the hierarchy is the goal to evaluate innovation plans in MEC. The next levels consist of the factors verified by the Delphi study of Meesapawong et al. [17]. Alternative plans evaluated by the factors are then arranged at the lowest level. Although the factors are assumed to be influencing factors fitting to Thai public R\&D, MEC's managers are expected to approve and rearrange the factors in the hierarchy. The approved hierarchy is used as the model in developing the AHP questionnaire asking the respondents to compare the importance of the factors in the hierarchy, and then 
evaluate the impact of alternative plans on the factors. The scale of pairwise comparison in the AHP uses integer ' 1 ' to ' 9 ' to represent the intensity of importance over another factor ranging from equal importance to extreme importance [19]. The AHP questionnaire asks each expert to compare importance amongst factors: which factor is more important, and how much more? The answers of each expert represented in ratio scale are then transferred to a matrix. The validity of AHP is approved by 'Consistency Ratio (C.R.)' calculated to reflect the confidence in the priorities derived from a pairwise matrix. The acceptable consistency ratio should be less than 0.10 [18], [24]. The consistency ratio is calculated from equation (1). If a consistency ratio of a matrix is unacceptable, revisions are called for.

$$
C . R .=\frac{\left(\lambda_{\max }-n\right) /(n-1)}{R . I .} .
$$

where: $\lambda_{\max }=\max$ eigenvalue of matrix $; n=$ matrix size $;$ R.I. $=$ random index [24].

Each question yields a set of matrices results from individual experts, hence the set of matrices need to be aggregated into a group's matrix by deriving geometric means. The importance priorities of each group's matrix are then derived from the principal eigenvector of the matrix [18]. The summation of local priorities in each matrix (or each hierarchical level) is equal to 1 . Each local priority needs to be converted to global priority by multiplying with the priority of its parent's priority. The sum of global priorities of all factors in a hierarchy is equal to 1 .

The impacts of alternative plans are rated in pairs with respect to each of the subfactors. Similar to importance priorities, impact weights of alternative plans $\left(a_{m n}\right)$ are calculated from the eigenvectors of group's matrices where total impact weight of all alternative plans is equal to 1 . Basically, the alternatives are evaluated by using the composite scores which each alternative contributes to all the criteria in the hierarchy [18]. The alternative which shows the highest composite score is the most likely selected alternative. The composite scores are the product of impact multiplied by importance as shown in equation (2).

$$
C m=\sum_{n=1}^{n} a_{m n} * g_{n}
$$

where: $a_{m n}=$ impact weight of alternative plan $m$ with respect to factor $n$

$g_{n} \quad=$ global priority of factor $n$

\section{$4 \quad$ Results}

Discussion with top management in MEC resulted in a five-level hierarchy model (Fig. 1) the first level (H1) of which is the goal of the hierarchy model to evaluate innovation plans in MEC. The second level $(\mathrm{H} 2)$ is constructed from four main dimensions of MEC: mission, internal $R \& D$, collaboration and management. The third and fourth levels are composed of factors verified by the MEC's managers. The 
fifth level of the hierarchy is arranged for alternative plans which are hypothesised plans of innovation management that are conceived by making assumptions about current and future trends of MEC. There are 3 plans which focus on different orientations (a) knowledge orientation focusing on for academic excellence (b) societal orientation focusing on societal values and (c) commercial orientation focusing on commercial values of research products. As shown in the hierarchies (Fig. 1), there are 24 sub-factors arranged in the third (H3) and the fourth level (H4) by which alternative plans are evaluated. Group's judgments regarding unequal importance of the factors are presented in terms of 'Global priorities $(G)$ '. The results show that the 'Commercial orientation (Plan C)' has the highest composite score at 0.4871, while the composite score of the 'Societal orientation, (Plan S)' and the 'Knowledge orientation (Plan K)' are 0.3369 and 0.1760 , respectively.

\begin{tabular}{|c|c|c|}
\hline $\mathrm{H} 1$ & To evaluate innovation plans in MEC & \\
\hline $\mathrm{H} 2$ & Mission & $(\mathrm{G}=0.3997)$ \\
\hline & H3 Scope & $(\mathrm{G}=0.1136)$ \\
\hline & H3 Strategy & $(\mathrm{G}=0.0937)$ \\
\hline & H3 Continuous improvement & $(\mathrm{G}=0.0687)$ \\
\hline & H4 Feedback & $(G=0.0462)$ \\
\hline & \begin{tabular}{|l|l|} 
H4 Standardisation \\
\end{tabular} & $(G=0.0225)$ \\
\hline & H3 Organisational benefit from strategy & $(G=0.0441)$ \\
\hline & H3 Societal benefit from strategy & $(\mathrm{G}=0.0796)$ \\
\hline & Internal R\&D & $(G=0.2176)$ \\
\hline & H3 Roadmap & $(\mathrm{G}=0.0531)$ \\
\hline & H3 Technological proficiency & $(\mathrm{G}=0.0527)$ \\
\hline & $\begin{array}{ll}\text { H3 } & \text { R\&D resource } \\
\end{array}$ & $(G=0.0630)$ \\
\hline & H3 Organisational benefit from R\&D & $(\mathrm{G}=0.0199)$ \\
\hline & \begin{tabular}{|l|l|} 
H4 & Financial benefit from R\&D \\
\end{tabular} & $(\mathrm{G}=0.0139)$ \\
\hline & H4 NonFinancial benefit from R\&D & $(\mathrm{G}=0.0060)$ \\
\hline & H3 Societal benefit from R\&D & $(\mathrm{G}=0.0289)$ \\
\hline & Collaborative projects (Co.) & $(G=0.0942)$ \\
\hline & H3 Selection \& evaluation criteria & $(G=0.0169)$ \\
\hline & $\begin{array}{ll}\text { H3 } & \text { Resource for Co. } \\
\end{array}$ & $(\mathrm{G}=0.0229)$ \\
\hline & H3 Network strength & $(\mathrm{G}=0.0170)$ \\
\hline & H3 Organisational benefit from Co. & $(\mathrm{G}=0.0153)$ \\
\hline & - H4 Financial benefit from Co. & $(G=0.0059)$ \\
\hline & H4 NonFinancial benefit from Co. & $(\mathrm{G}=0.0094)$ \\
\hline & H3 Societal benefit from Co. & $(\mathrm{G}=0.0220)$ \\
\hline$-\mathrm{H} 2$ & Management & $(G=0.2885)$ \\
\hline & H3 Formal management tools & $(\mathrm{G}=0.0711)$ \\
\hline & H4 Knowledge management & $(G=0.0241)$ \\
\hline & H4 Innovation management & $(\mathrm{G}=0.0470)$ \\
\hline & H3 Resource for managerial work & $(G=0.0579)$ \\
\hline & H3 Environment for managerial work & $(G=0.0734)$ \\
\hline & H3 Management-led organisational bene & $\mathrm{t}(\mathrm{G}=0.0380)$ \\
\hline & H3 Management-led societal benefit & $(\mathrm{G}=0.0482)$ \\
\hline & Alternative plans & \\
\hline & ledge $=0.1760$, Societal $=0.3369$, Comn & rcial $=0.4871$ \\
\hline
\end{tabular}

Fig. 1. Hierarchy model for innovation management in MEC 


\section{Discussion}

The AHP study shows that the commercial orientation has the greatest impact on innovations. As a taxpayer-funded organisation, MEC cannot ignore the importance of collaboration-related factors and the innovation plan focusing on societal values. Hence, a sensitivity analysis is performed to establish whether any change in priority of any factor could make the societal orientation plan become the most impact plan on innovations. The sensitivity tests with respect each dimension shows that changes in ranks of plans are only found in the collaboration dimension (Fig. 2). The societal orientation becomes the most impact plan on innovations when the priority of collaboration is more than $43 \%$, whereas the original value is $9.42 \%$. There is a large gap to bring the priority of collaboration to the point that made the societal orientation plan become more important in terms of impact to the overall innovation factors. To highlight the collaboration dimension, MEC may start from understanding the subfactors under the dimension. Fig. 3 reveals similar patterns of impact and importance of sub-factors. This means that MEC have already distributed priorities to the subfactors corresponding to the impact. However, to increase in overall importance of collaboration-related factors by keeping the same fraction amongst them is essential for MEC to improve its innovation capability and satisfy societal aspirations.

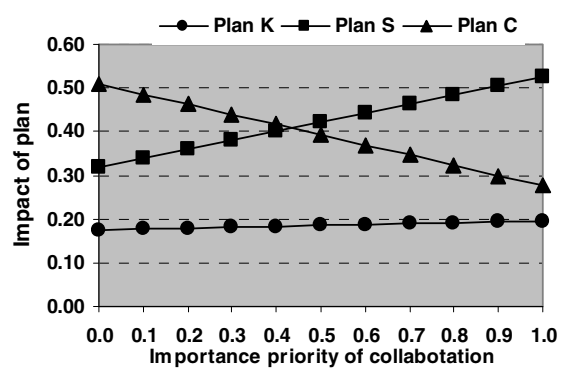

Fig. 2. Sensitivity of innovation plans with respect to collaboration

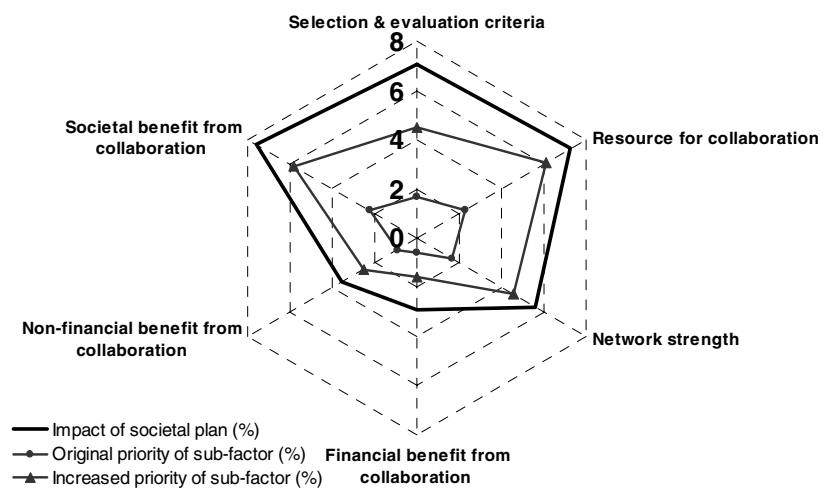

Fig. 3. Impact and importance of collaboration-related factors 
The AHP findings in MEC can be further applied for particular activities in collaboration such as selecting collaborative projects based on the collaborationrelated factors obtained from the paper (as shown in Fig. 4).

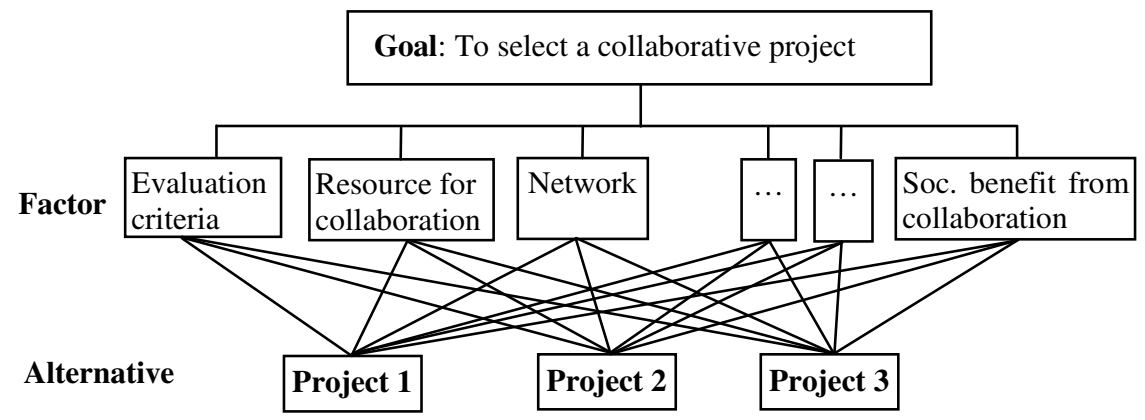

Fig. 4. A pre-determined hierarchy for selecting collaborative projects

\section{Conclusions}

The paper addresses the research gap for innovation management in public R\&D by underling the collaboration-related factors. A public R\&D case study, namely MEC, provides an innovation management model arranged by AHP. The model is established to assess three innovation plans in MEC: knowledge, societal and commercial plans. The model yields different weights of collaboration-related factors and other influencing factors on innovation. With respect to all factors, the commercial plan shows the highest impact score on innovation factors. However, the sensitivity analysis provides a view that MEC can improve its innovation capability and satisfy societal aspirations by raising the priorities of collaboration-related factors. Additionally, there is a large gap to bring the priority of collaboration to the point that made the societal orientation plan become the most impact plan.

The AHP study in MEC can be further elaborated by establishing a new AHP model, the goal of which is to implement the plan of societal orientation such as selecting collaborative projects. Nevertheless, this study is limited at the stage of innovation planning and is not extended to the implement stage such as selecting collaborative projects.

Although, the AHP model is specifically designed for MEC, other public R\&D organisations could use this model as a pre-determined hierarchy model to develop hierarchy models suited to their organisational environment because the factors are originally gathered from research of public R\&D in developed and developing countries before refinement by a Thai Delphi panel. The authors hope that the present paper will contribute to the ongoing improvement of innovation management in public R\&D. 


\section{References}

1. Shavinina, L.V.: The international handbook on innovation. Pergamon, Oxford (2003)

2. Hoonsopon, D., Ruenrom, G.P.: The Empirical Study of the Impact of Product Innovation Factors on the Performance of New Products: Radical and Incremental Product Innovation. The Business Review 12, 155-162 (2009)

3. Denhardt, R.B., Denhardt, J.V.: The New Public Service: Serving Rather than Steering. Public Administration Review 60, 549-559 (2000)

4. Greener, I.: Public management: a critical text. Palgrave Macmillan, Basingstoke (2009)

5. Cozzarin, B.P.: Data and the measurement of R\&D program impacts. Evaluation and Program Planning 31, 284-298 (2008)

6. Vorakulpipat, C., Rezgui, Y., Hopfe, C.J.: Value creating construction virtual teams: A case study in the construction sector. Automation in Construction 19, 142-147 (2010)

7. Burnes, B.: Managing change: a strategic approach to organisational dynamics, 4 th edn. Financial Times, Harlow (2004)

8. Dierkes, M., Antal, A.B., Child, J., Nonaka, I.: Handbook of organizational learning and knowledge. Oxford University Press, Oxford (2001)

9. Meesapawong, P., Rezgui, Y., Li, H.: Perceiving societal value as the core of innovation management in public research and development organizations. In: The 5th International Conference on Management of Innovation and Technology, Singapore, pp. 312-317 (2010)

10. Tidd, J., Bessant, J.: Managing Innovation: Integrating Technological, Market and Organizational Change, 4th edn. John Wiley \& Sons, Chichester (2009)

11. Nieto, M.J., Santamaría, L.: The importance of diverse collaborative networks for the novelty of product innovation. Technovation 27, 367-377 (2007)

12. Tsai, K.-H.: Collaborative networks and product innovation performance: Toward a contingency perspective. Research Policy 38, 765-778 (2009)

13. Mowery, D.C.: The changing structure of the US national innovation system: implications for international conflict and cooperation in R\&D policy. Research Policy 27, 639-654 (1998)

14. Daniel, H.Z., Hempel, D.J., Srinivasan, N.: A model of value assessment in collaborative R\&D programs. Industrial Marketing Management 31, 653-664 (2002)

15. Trott, P.: Innovation management and new product development, 3rd edn. Financial Times Prentice Hall, NJ (2005)

16. Osterwalder, A., Pigneur, Y.: Clarifying Business Models: Origins, Present, and Future of the Concept. Communications of AIS, 1-25 (2005)

17. Meesapawong, P., Rezgui, Y., Li, H.: Factors influencing innovation management in public research and development. Submitted manuscript in R\&D Management Journal (2011)

18. Saaty, T.L.: The Analytic Hierarchy Process. McGraw-Hill, New York (1980)

19. Saaty, T.L., Vargas, L.G.: Models, Methods, Concepts and Applications of the Analytic Hierarchy Process. Kluwer Academic, Boston (2000)

20. Turban, E.: Decision support and expert systems: management support systems, 4th edn. Prentice-Hall, NJ (1995)

21. Chin, K.S., Pun, K.F., Xu, Y., Chan, J.S.F.: An AHP based study of critical factors for TQM implementation in Shanghai manufacturing industries. Technovation 22, 707-715 (2002)

22. Saaty, T.L., Tran, L.T.: On the invalidity of fuzzifying numerical judgments in the Analytic Hierarchy Process. Mathematical and Computer Modelling 46, 962-975 (2007)

23. Hayne, S.C., Pollard, C.E.: A comparative analysis of critical issues facing Canadian information systems personnel: a national and global perspective. Information \& Management 38, 73-86 (2000)

24. Saaty, T.L., Ozdemir, M.S.: Why the magic number seven plus or minus two. Mathematical and Computer Modelling 38, 233-244 (2003) 